\title{
Editorial
}

\section{Medical humanities and philosophy of medicine}

Over the past 30 years - starting in the United States - an interest in 'medical humanities' has emerged. In the same period modern 'philosophy of medicine' developed. Although the medical humanities are sometimes presented under the flag of medical philosophy, there are good reasons to consider these fields separately. The first part of this fourth issue of volume 10 is a thematic section about the relationship between medical humanities and philosophy of medicine. This thematic section stems from the twentieth annual conference of the European Society for Philosophy of Medicine and Health Care (ESPMH) held in Helsinki, Finland, in August 2006. The four papers in this thematic section are developed from papers presented at that conference. The content of this thematic section will be further introduced by our guest editor William Stempsey.

The first paper of the remaining scientific contributions was written by Erik Malmqvist from Linköping, Sweden. With the paper 'Analysing our qualms about "designing" future persons: autonomy, freedom of choice, and interfering with nature' Erik Malmqvist won the first prize in the annual contest for young scholars started by the European Society for Philosophy of Medicine and Health Care (ESPMH) in 2005. ESPMH prizes are awarded annually to scholars younger than 35 for a scientific contribution on ethical, epistemological, or other philosophical issues related to medicine and health care. Erik Malmqvist focuses on modern technological developments in genetics and assisted reproduction that increase the possibilities of choosing the kind of persons that will be brought into existence. One of the questions addressed by him is why our thoughts about therapeutic genetic interventions and non-genetic enhancement (for instance education) are not accompanied by the same intuitive uneasiness. He argues that this question cannot be adequately answered by using the concepts of autonomy and freedom of choice. Instead, he suggests, an alternative answer might begin with a reflection on the notion of nature. Erik Malmqvist's arguments are derived from Martin Heidegger's critique of modern technology and Hans Jonas's moral philosophy.

The next article is an invited paper. In 'Geneticization and bioethics: advancing debate and research' Vilhjálmur Árnason and Stefan Hjörleifsson analyse the role that the concept of geneticization has played in discussions about health care, bioethics and society. The term geneticization has been used by social scientists, philosophers and other scholars for almost two decades. However, geneticists are quite reluctant to use this term. The main problem is that it is not clear what exactly is meant by 'geneticization' and whether this term necessarily has a negative meaning. Vilhjálmur Árnason and Stefan Hjörleifsson place the concept of geneticization in an historical context and make a comparison with the older debate on medicalization that started in the 1970s. They demonstrate how a concept such as geneticization can play an important role in addressing fundamental ethical issues related to the development of medical genetics. They argue that future research on geneticization should be informed by recent debates about medicalization and that a wider reading of geneticization should inspire a critical analysis of the sociocultural preconditions under which genetics is currently evolving

The next two papers deal with the problem of organ donation. Mare Knibbe, Els Maeckelberghe and Marian Verkerk present some findings of a qualitative empirical-ethical study about living parental liver donation. They interviewed 25 respondents in 12 families. The parents' perception of having no choice and strong emotions such as fear about the prospect of living liver donation were two of the important findings of their study. In view of these results one can doubt whether the consent of the parents is genuinely voluntary. The authors' normative framework consists of an interpretation of 'moral agency', in which relations are seen as constitutive of moral agency. On the basis of this framework they argue that neither the experience of having no choice nor having strong emotions should be seen as compromises of a voluntary consent. David Isch also tackles the 
problem of shortage of organs. He focuses in particular on the recovery of organs from patients with a circulatory determination of death, which is one of several effective alternative approaches recommended to reduce the supply-and-demand gap. The practice of recovering organs from these patients follows the dead donor rule. According to David Isch, the concern whether a person is actually dead at the moment of organ recovery dissolves with the readiness to give up the definitive commitment to the dead donor rule. The author's solution is based on a Heideggerian existential phenomenological and hermeneutic framework. Isch makes the locus of ethical concern "the donor-recipient as unitary life" and introduces a new notion of "respect for all life" in which organs do not correlate to the "living-time" of an organism (body), but to the organ's "life-time capability".

In the final paper in this issue Norbert Steinkamp and co-authors discuss the question if and how Healthcare Ethics Committees (HECs) should be regulated. The paper is based on a description and analysis of the situation in eight EC member countries. It is suggested that regulation of HECs should be central and weak. Moreover, the independence of HECs to deliberate about ethical questions and to give solicited and unsolicited advice should be supported.

\section{Wim Dekkers and Bert Gordijn}

